\title{
Consumo energético de salas de escritório climatizadas de modo misto em São Paulo: considerações sobre o projeto
}

\author{
Energy consumption of mixed-mode air conditioned \\ cellular offices in São Paulo: considerations about the \\ design
}

\section{Caroline Antonelli Santesso Karin Maria Soares Chvatal}

\section{Resumo \\ $\mathbf{N}$}

a literatura há poucos estudos sobre edifícios climatizados de modo misto (ou com ventilação híbrida) com estratégias simples de projeto. Dessa forma, esta pesquisa avalia o impacto de parâmetros arquitetônicos (formato da sala, tamanho e orientação das aberturas) e de uso (densidade de carga de equipamentos e temperatura de acionamento do arcondicionado) no desempenho energético de salas de escritório de modo misto na cidade de São Paulo. O método consistiu em um levantamento de dados dessa tipologia de edifício, caracterizando os modelos de estudo, e simulações paramétricas no programa EnergyPlus. Verificou-se que o uso da ventilação híbrida proporcionou reduções de até $52 \%$ no consumo energético do arcondicionado para resfriamento. Ao se adotar essa estratégia, é importante associar a forma da sala à área da janela. Menores consumos energéticos foram observados para as combinações de salas estreitas e profundas com janelas maiores ou de salas menos profundas e mais largas com janelas menores. Contudo, a diminuição da área efetiva para ventilação alterou essas conclusões, tendo sido obtido menor consumo de energia sempre com janelas menores. Este trabalho indica que a combinação adequada dos parâmetros estudados pode gerar projetos com menor consumo energético, o que auxilia na concepção dessa tipologia de edifício.

Palavras-chave: Consumo de energia. Ventilação híbrida. Modo misto. Edifícios de escritórios. Simulação computacional.

\begin{abstract}
The literature presents only a limited number of studies on mixed-mode airconditioned buildings (or with hybrid ventilation) with simple design strategies. Thus, this project evaluates the impact of architectural (room shape, window size and orientation) and usage parameters (equipment load density and air conditioning activation temperature) on the thermal performance of mixed-mode cellular offices in the city of São Paulo. The method consisted in characterising the studied models using a data survey of this building type and parametric computer simulations using the EnergyPlus software. The method demonstrated that hybrid ventilation led to a decrease of up to $52 \%$ in the energy consumption of the air conditioning used for cooling. When adopting such strategy, it is important to associate the room's shape to the window area. Lower energy consumption levels were observed for the combinations of deep and narrow rooms with larger windows or less deep and wider rooms with smaller windows. However, the decrease in the effective area for ventilation changed these conclusions, always yielding lower energy consumption with smaller windows. Hence, this study indicates that an adequate combination of parameters can result in designs that consume less energy, assisting in the design of this type of building.
\end{abstract}

Recebido em 30/10/17 Aceito em 30/01/18

Keywords: Energy consumption. Hybrid ventilation. Mixed-mode. Office buildings. Computer simulation. 


\section{Introdução}

Com o intuito de promover maior eficiência energética e manter o conforto térmico dos usuários em edifícios de escritórios, estudos indicam a importância de se utilizar a ventilação híbrida como forma de climatização do ambiente interior em vez do uso constante de sistemas mecânicos (BRAGER; RING; POWELL, 2000; GONÇALVES; BODE, 2015; MENDLER; ODELL; LAZARUS, 2006; ROAF; CRICHTON; NICOL, 2009; RUPP; GHISI, 2013a; SALCIDO; RAHEEM; ISSA, 2016).

A estratégia denominada ventilação híbrida ou modo misto consiste na possibilidade de se utilizar em um mesmo ambiente e/ou edificação a ventilação natural complementada por sistemas mecânicos de climatização artificial de ar. Essa estratégia em edifícios comerciais, além de possibilitar economia de energia, diminui problemas relacionados à qualidade do ar e pode aumentar a satisfação dos usuários. No entanto, sua utilização deve se restringir a locais com baixo ruído, poluição e/ou poeira (BRAGER; RING; POWELL, 2000; CENTER..., 2017).

Uma das formas de se prover ventilação no modo misto consiste no uso de janelas comuns que podem ser operadas por usuários. Esse tipo de janela é um elemento de uso frequente na envoltória das edificações, e seu dimensionamento deve ser feito de forma adequada, pois pode fornecer tanto a ventilação natural quanto a entrada de luz, de forma a auxiliar na redução do consumo energético do ambiente (GHISI;TINKER; IBRAHIM, 2005; RUPP; GHISI, 2017). Além disso, sua utilização tem maior potencial em ambientes menores, pois, além de proporcionar uma ventilação mais eficaz, permite maior autonomia ao usuário, para que ele se adapte e mantenha o conforto térmico necessário (MENDLER; ODELL; LAZARUS, 2006).

Nesse sentido, salas de escritório com janelas operáveis podem proporcionar maior eficiência da ventilação híbrida e gerar um projeto arquitetônico que englobe economia de energia e maior satisfação dos usuários.

No cenário internacional, muitos trabalhos indicam a economia de energia de edifícios com estratégias de ventilação híbrida mais complexa (ROWE, 2003; MENASSA; TAYLOR; NELSON, 2013; HU; KARAVA, 2014). Em um edifício real no sul da China, com a ventilação natural através de dutos e sistema mecânico de resfriamento, a utilização da estratégia da ventilação híbrida permitiu estender o tempo de uso da ventilação natural, chegando a economizar até $35 \%$ da energia requerida para resfriamento pelo sistema mecânico, além de melhorar a qualidade do ar interno (JI; LOMAS; COOK, 2009). Em outro estudo, realizado em Montreal, no Canadá, também com um edifício de modo misto mais complexo, verificou-se que, com o uso da estratégia híbrida, o edifício economizava $30 \%$ do resfriamento requerido pelo sistema mecânico no átrio e nos corredores durante o período de verão (KARAVA et al., 2012).

Contudo, Brager, Ring e Powell (2000) alertam que sistemas muito complexos de condicionamento artificial de ar e de ventilação natural podem gerar aumento de custo do edifício, sendo que é possível economizar energia com a combinação de estratégias simples de ventilação híbrida, conforme observaram Ezzeldin e Rees (2013). Os autores verificaram que em edifícios de modo misto localizados em cidades representativas do clima árido, quando os usuários têm o controle das janelas e uma atitude mais consciente, é possível economizar mais de $40 \%$ da energia anual consumida pelo sistema mecânico simplesmente por alterná-lo com o uso da ventilação natural (EZZELDIN; REES, 2013).

O Brasil possui condições climáticas favoráveis para o uso da ventilação híbrida, principalmente através de janelas operáveis pelo usuário; contudo, existem poucos estudos nacionais que consideram esse contexto. Rupp e Ghisi (2012, 2013b) compararam vários modelos de salas de escritório com diferentes modos de operação de climatização (ar condicionado constante/modo misto) e iluminação (artificial/natural) para a cidade de Florianópolis, SC. Os modelos analisados continham três diferentes geometrias (relação entre a largura e a proporção do ambiente L:P de 1:1, $1: 2,2: 1)$, três tamanhos de salas por geometria (pequenas - até $12 \mathrm{~m}^{2}$; médias - até $76 \mathrm{~m}^{2}$; e grandes - até $473 \mathrm{~m}^{2}$ ); quatro orientações (norte, sul, leste e oeste); e percentual de área de abertura da janela (PAF) variando de $10 \%$ a $100 \%$. A partir da simulação computacional com os programas EnergyPlus (DEPARTMENT..., 2014) e Daysim, os autores verificaram redução entre $21,7 \%$ e $64,9 \%$ do consumo total nos modelos comparandose casos operando com modo misto e iluminação natural complementada pela artificial com casos com o ar condicionado constante e iluminação artificial. Já no trabalho de Brugnera (2014), em que se utilizaram os mesmos programas de simulação, os modelos considerados (sala de $34 \mathrm{~m}^{2}$ e PAFs de $30 \%, 50 \%$ e $80 \%$ ) foram simulados para as cidades de São Carlos, SP, e Natal, RN. Destaca-se a comparação dos modelos operando

120 Santesso, C. A.; Chvatal, K. M. S. 
com ar condicionado constante e com modo misto, ambos utilizando sistema de iluminação artificial dimerizável eficiente, com o aproveitamento da iluminação natural. Com os modelos operando no modo misto foi possível reduzir em $30 \%$ o consumo do ar-condicionado para a cidade de São Carlos, o que representa $26 \%$ do consumo da energia total anual. Já para Natal a forma analisada do sistema de ventilação híbrida não foi eficiente devido às elevadas temperaturas desse clima e às limitações das temperaturas para controle da ventilação estabelecidas.

A utilização de estratégias de ventilação híbrida é uma área de estudo recente, havendo poucos trabalhos internacionais e nacionais que analisam edifícios de modo misto com estratégias simples de projeto. Dessa forma, o objetivo deste trabalho é avaliar o impacto de três principais parâmetros de projeto (formato da sala, tamanho e orientação solar das aberturas na fachada) no acionamento, potencial de economia e consumo de energia do arcondicionado operando no modo misto em salas de escritório com janelas operáveis na cidade de São Paulo. Adicionalmente foram realizadas simulações extras para se observar a influência no consumo energético da alteração da área efetiva de abertura para ventilação e de parâmetros de uso (densidade de carga térmica de equipamentos e temperatura de controle do ar-condicionado).

\section{Método}

O método consiste na análise do impacto dos parâmetros de projeto no acionamento do arcondicionado operando durante todo o ano, nos horários de ocupação, de forma constante(modo constante) e no modo misto (modo misto), e na ocorrência de ventilação natural no modo misto de salas de escritório na cidade de São Paulo. Essa análise foi realizada a partir de simulações computacionais, cujo principal programa adotado foi o EnergyPlus 8.2 (DEPARTMENT..., 2014), validado pela ANSI/ASHRAE Standard 140 (AMERICAN..., 2004). As principais definições utilizadas para as simulações são apresentadas a seguir.

\section{Clima}

Considerou-se o arquivo climático da cidade de São Paulo (epw) nas simulações, elaborado por Roriz (2012) e atualizado pelo Laboratório de Eficiência Energética em Edificações (LabEEE) juntamente com DruCrawley e Linda Lawrie (LABORATÓRIO...; CRAWLEY; LAWRIE, 2015). A cidade de São Paulo (latitude de $23^{\circ} 85^{\prime}$ S e altitude de $792 \mathrm{~m}$ ) está situada na zona bioclimática 3 de acordo com a norma brasileira NBR 15220-3 (ABNT, 2005a). Seu clima na classificação climática de Köppen é o Cwa, caracterizado por ter inverno seco e verão quente e chuvoso (CENTRO..., 2016). A partir das informações geradas com o arquivo climático, a Figura 1 apresenta as médias da temperatura e da umidade relativa do ar ao longo dos meses do ano, e a Figura 2, a rosa dos ventos. As médias mínimas mensais da temperatura do ar variam de $13^{\circ} \mathrm{C}$ a 19 ${ }^{\circ} \mathrm{C}$, e as máximas de $21^{\circ} \mathrm{C}$ a $28^{\circ} \mathrm{C}$. As médias da umidade relativa do ar são maiores que $70 \%$ na maior parte do ano, e a direção predominante dos ventos encontra-se entre leste e sudeste.

Figura 1 - Médias mensais da temperatura e da umidade relativa do ar em São Paulo

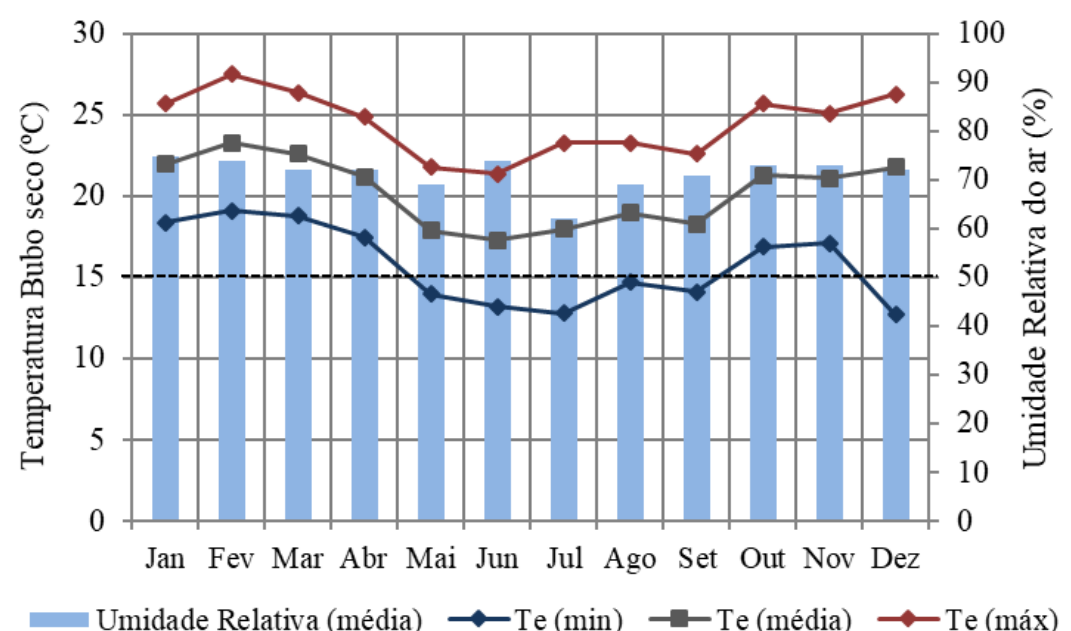

Fonte: adaptada de EPvieW (RORIZ; RORIZ, 2015). 
Figura 2 - Rosa dos ventos para a cidade de São Paulo

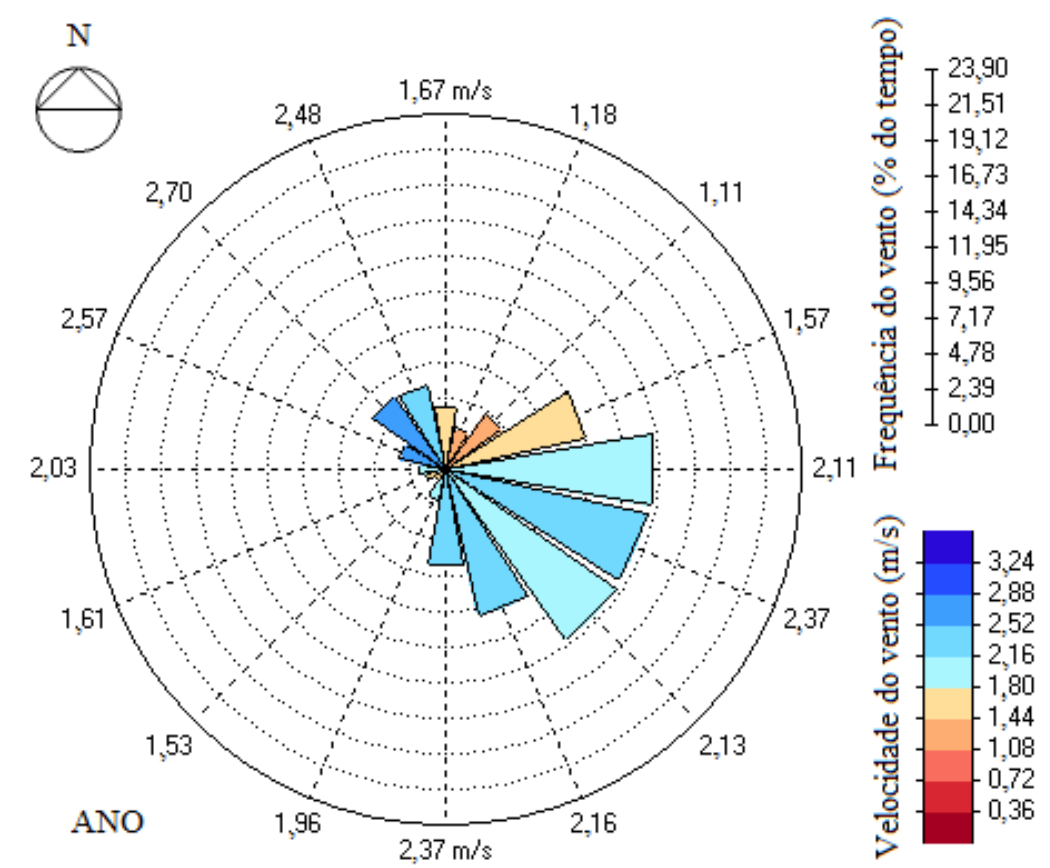

Fonte: adaptada de EPvieW (RORIZ; RORIZ, 2015).

\section{Geometria dos modelos}

Para se definirem os modelos de salas de escritório realizou-se um levantamento de dados na base da empresa Buildings (2016). Essa empresa denomina as salas de escritório de menor dimensão, que são as analisadas neste trabalho, como "saletas comerciais (offices)", que consistem em ambientes pequenos, com área menor que $100 \mathrm{~m}^{2}$ (BUILDINGS, 2016). Dessa forma, elencaram-se características de 55 edifícios com salas de escritório, localizados na cidade de São Paulo. Essas características consistiram em:
(a) região de São Paulo (Bairro);
(b) nome e ano de construção dos edifícios;
(c) quantidade de andares;
(d) área total do edifício $\left(\mathrm{m}^{2}\right)$;
(e) área total por andar $\left(\mathrm{m}^{2}\right)$;
(f) área de salas de escritório $\left(\mathrm{m}^{2}\right)$;
(g) pé-direito $(\mathrm{m})$; e
(h) sistema de condicionamento de ar.

Verificou-se que as edificações possuíam salas de escritório com áreas de piso de no mínimo $13 \mathrm{~m}^{2} \mathrm{e}$ de no máximo $67 \mathrm{~m}^{2}$, commédia de $36 \mathrm{~m}^{2}$, e, na grande maioria, pé-direito de $2,7 \mathrm{~m}$ e uso de arcondicionado do tipo split. A partir desse levantamento e da revisão de literatura foram definidos cinco modelos para as simulações. Esses modelos possuem a mesma área de uma sala de escritório média de $36 \mathrm{~m}^{2}$, pé-direito útil de $2,7 \mathrm{~m}$ e diferentes proporções (relação entre a dimensão da largura (L) e a profundidade do ambiente (P), $\mathrm{L}: \mathrm{P}$, de 1:3, 1:2, 1:1, 2:1, 3:1). A escolha de um único tamanho de sala $\left(36 \mathrm{~m}^{2}\right)$ se justifica devido ao fato de este ser um dado inicial de uso frequente fornecido para a elaboração de projetos. Dessa forma, poder utilizarcinco proporções (sala quadrada 1:1, salas profundas 1:2 e 1:3, e salas largas 2:1 e 3:1) permitiu explorar todas as possibilidades a partir de uma mesma área (Figura 3).

Para as simulações assumiu-se que um edifício de salas de escritório é composto de pavimentos similares, com repetição de módulos, que podem ser considerados representativos do edifício como um todo (REINHART; WIENOLD, 2011; GHISI, 2002). Assim, o módulo desta pesquisa é composto de duas salas idênticas (referentes aos cinco modelos apresentados), com janelas na fachada externa e um corredor central. A janela presente em apenas uma fachada, voltada ao exterior, representa a solução arquitetônica mais comum observada para esse tipo de edificação. Dessa forma, o módulo é constituído por três zonas térmicas, onde o teto, o piso e as paredes internas são considerados adiabáticos. $\mathrm{O}$ entorno foi desconsiderado, configurando-se o terreno na simulação como "cidade". Foram simuladas duas orientaçõesem relação ao norte para esse módulo, de forma que as janelas estivessem orientadas ao norte e ao sul, e ao leste e ao oeste(Figura 
4).Variou-se o percentual de área de abertura na fachada (PAF), em todos os modelos, de 10\%, $40 \%, 70 \%$ e $100 \%$ (Figura 5). Essa variação de área envidraçada (considerando o espaço útil da fachada), apesar de muitas vezes não representar a realidade, permite uma análise mais completa e auxilia nas tomadas de decisões de projeto.

Figura 3 - Geometria dos modelos de salas de escritório

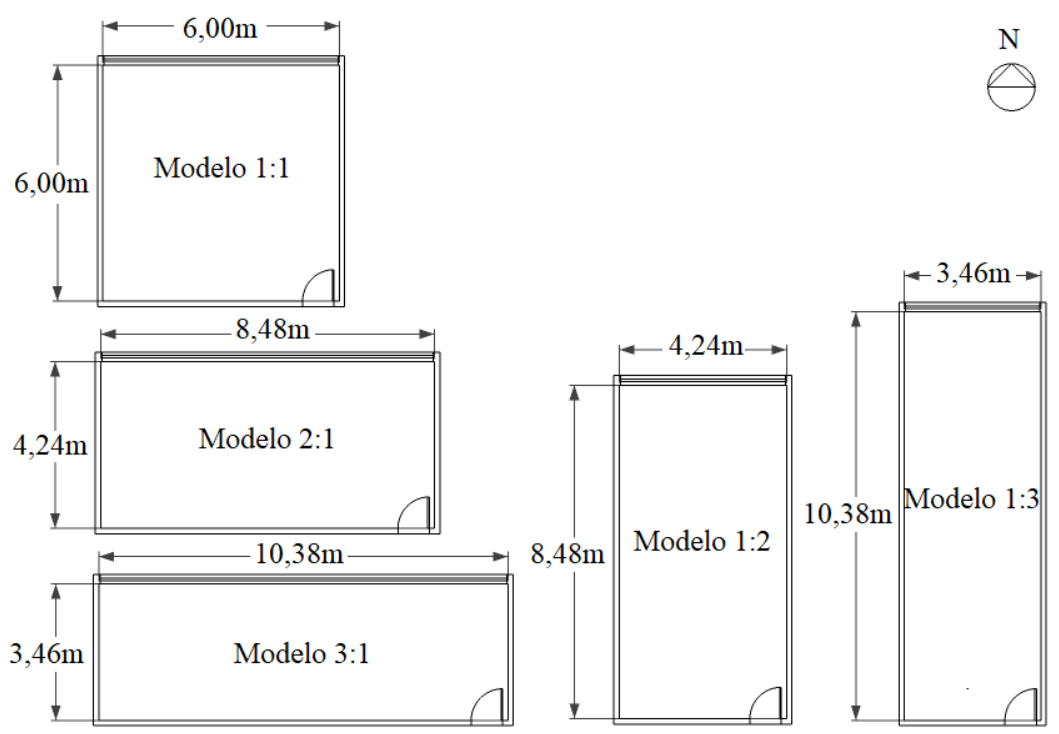

Figura 4 - Módulo de simulação
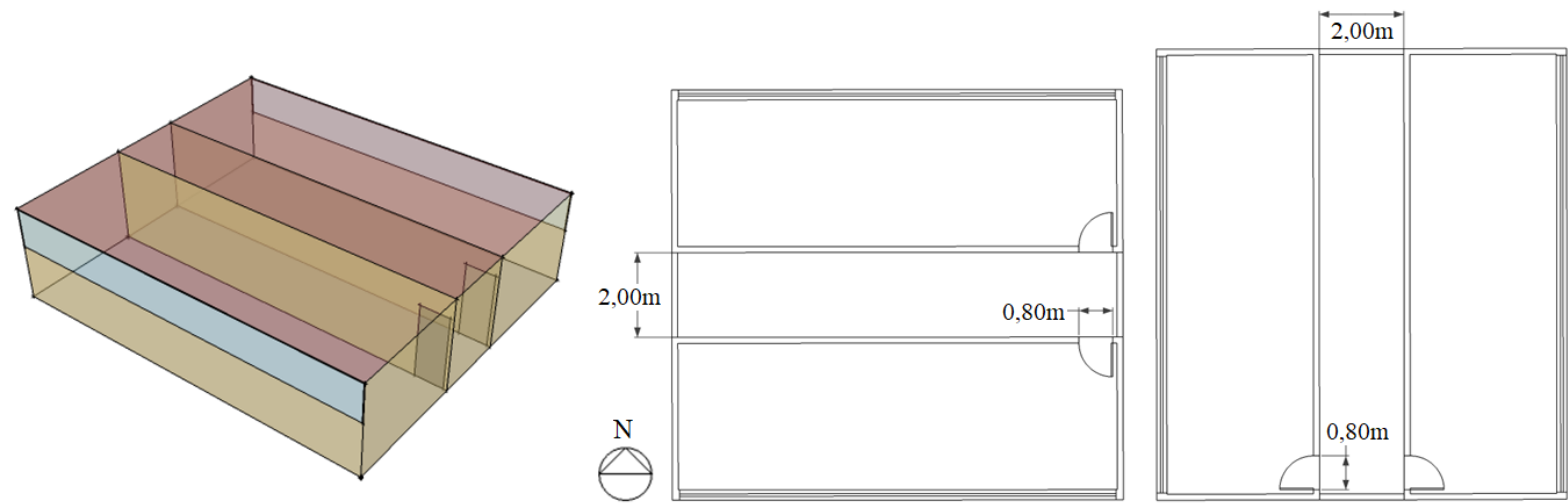

Figura 5 - Percentual de área de abertura na fachada
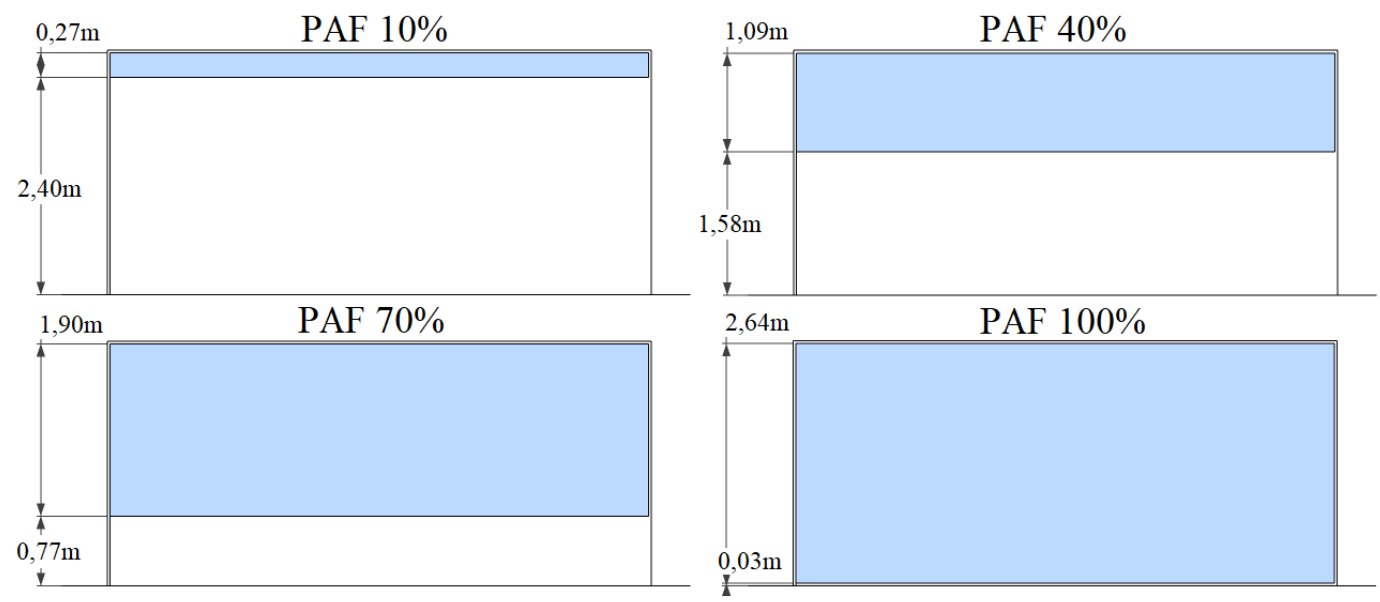


\section{Componentes construtivos}

A caracterização dos componentes construtivos foi escolhida de acordo com características usuais de edifícios comerciais eutilizando como referência o trabalho de Brugnera (2014), em que o modelo de edifício foi definido a partir de um levantamento de edifícios de escritórios realizado por Carrières (2007). As propriedades dos componentes construtivos - transmitância térmica (U), capacidade térmica (CT), condutividade térmica $(\lambda)$, calor específico (c) e absortância solar visível $(\alpha)$ - das salas de escritório simuladas (paredes, piso e laje) foramcalculadas a partir da norma NBR 15220-2 (ABNT, 2005b) e são apresentadas na Tabela 1.

\section{Ganhos internos}

A Tabela 2 indica os valores adotados para o cálculo dos ganhos de calor internos devido aos usuários, equipamentos e iluminação artificial. Os usuários (cinco pessoas por sala) estiveram presentes no horário convencional de trabalho, das $8 \mathrm{~h}$ às $18 \mathrm{~h}$. Nesse período também os equipamentos são utilizados de forma constante, e a iluminação artificial é acionada sempre que necessário.

A iluminação artificial foi considerada dimerizável e eficiente na pesquisa, utilizada apenas para complementar a iluminação natural. Para isso foi realizada a simulação em outro programa, oDIVAfor-Rhino (SOLEMMA, 2014), que utiliza o algoritmo Radiance. Os resultados foram integrados ao EnergyPlus de forma manual, incluindo-se o arquivo do padrão de uso da iluminação artificial (.csv) gerado pelo DIVA-forRhino no grupo ScheduleFile do EnergyPlus. Esse procedimento foi necessário devido ao fato de que os métodos de cálculo do EnergyPlus superestimam a quantidade de luz natural no interior do ambiente, o que influencia diretamente o consumo de energia elétrica (RAMOS; GHISI, 2010).Assim, as lâmpadas são acionadas, de forma individual, quando não se atinge a iluminação considerada mínima para escritórios de 500 lux (ABNT, 2013) nas superfícies de trabalho, a uma altura de $0,75 \mathrm{~cm}$ do piso (ABNT, 2004). Dessa forma, a carga térmica da iluminação artificial varia de acordo com a quantidade de luz natural no ambiente.

\section{Funcionamento do ar-condicionado e da ventilação natural}

A modelagem do ar-condicionado operando, tanto durante todo o ano nos horários de ocupação de forma constante, modo constante, quanto no modo misto, foi realizada a partir do sistema mecânico ideal, que informa a quantidade de carga térmica necessária para manter o ambiente dentro das temperaturas estabelecidas. Para isso, os parâmetros foram configurados através da classe dos objetos HVAC Template do EnergyPlus.

Tabela 1 - Componentes construtivos

\begin{tabular}{|c|c|c|c|c|c|c|}
\hline $\begin{array}{c}\text { Compone } \\
\text { nte }\end{array}$ & Material & $\begin{array}{c}\mathbf{U} \\
\left(\mathbf{W} / \mathbf{m}^{2} \cdot \mathbf{K}\right) \\
\end{array}$ & $\begin{array}{c}\mathbf{C T} \\
\left(\mathbf{K} \mathbf{J} / \mathbf{m}^{2} . \mathbf{K}\right) \\
\end{array}$ & $\lambda(\mathbf{W} / \mathbf{m} . \mathbf{K})$ & c (J/kg.K) & $\alpha$ \\
\hline Cobertura & Laje de concreto $(8 \mathrm{~cm})$ & 3,31 & 176 & 1,75 & 1.000 & \multirow{7}{*}{$0,11^{*}$} \\
\hline \multirow{3}{*}{$\begin{array}{l}\text { Parede } \\
\text { Externa }\end{array}$} & $\begin{array}{l}\text { Argamassa exterior }(2,5 \\
\mathrm{cm})\end{array}$ & \multirow{3}{*}{2,62} & \multirow{3}{*}{323} & 1,15 & 1.000 & \\
\hline & $\begin{array}{l}\text { Bloco concreto } \\
\text { furado }(19 \mathrm{~cm})\end{array}$ & & & 1,75 & 1.000 & \\
\hline & $\begin{array}{l}\text { Argamassa interior }(2,5 \\
\mathrm{cm})\end{array}$ & & & 1,15 & 1.000 & \\
\hline \multirow{3}{*}{$\begin{array}{l}\text { Parede } \\
\text { Interna }\end{array}$} & Argamassa $(2,5 \mathrm{~cm})$ & \multirow{3}{*}{2,27} & \multirow{3}{*}{206} & 1,15 & 1.000 & \\
\hline & $\begin{array}{l}\text { Bloco de concreto furado } \\
(9 \mathrm{~cm})\end{array}$ & & & 1,75 & 1.000 & \\
\hline & Argamassa $(2,5 \mathrm{~cm})$ & & & 1,15 & 1.000 & \\
\hline \multirow{4}{*}{ Piso } & Brita $(3 \mathrm{~cm})$ & \multirow{4}{*}{3,08} & \multirow{4}{*}{281} & 0,7 & 800 & \multirow{4}{*}{-} \\
\hline & Concreto $(5 \mathrm{~cm})$ & & & 1,75 & 1.000 & \\
\hline & Argamassa $(2,5 \mathrm{~cm})$ & & & 1,15 & 1.000 & \\
\hline & Piso cerâmico $(0,5 \mathrm{~cm})$ & & & 1,05 & 920 & \\
\hline Porta & Madeira, 1 folha $(3,5 \mathrm{~cm})$ & \multicolumn{5}{|c|}{-} \\
\hline $\begin{array}{l}\text { Vidro } \\
\text { Simples }\end{array}$ & Incolor $(6 \mathrm{~mm}) * *$ & \multicolumn{5}{|c|}{-} \\
\hline
\end{tabular}

124 Santesso, C. A.; Chvatal, K. M. S. 
Tabela 2 - Ganhos internos

\begin{tabular}{|c|c|c|c|}
\hline \multicolumn{3}{|c|}{ Parâmetros relacionados aos ganhos internos } & Referências \\
\hline \multirow[b]{4}{*}{ Usuários } & \multirow{3}{*}{$\begin{array}{l}\text { Ocupação } \\
\left(\mathrm{m}^{2} / \text { pessoa }\right)\end{array}$} & \multirow{3}{*}{7} & NBR 16401-3 (ABNT, 2008a) \\
\hline & & & NBR 9077 (ABNT, 2001) \\
\hline & & & $\begin{array}{l}\text { Código de Obras e Edificações no município de São } \\
\text { Paulo (BRASIL, 1992) }\end{array}$ \\
\hline & $\begin{array}{l}\text { Taxa } \\
\text { metabólica } \\
\left(\mathrm{W} / \mathrm{m}^{2}\right)\end{array}$ & 65 & $\begin{array}{l}\text { Calor produzido de } 117 \mathrm{~W}\left(65 \mathrm{~W} / \mathrm{m}^{2} \times 1,8 \mathrm{~m}^{2}\right) \text {, } \\
\text { considerando que a média área de pele de uma } \\
\text { pessoa corresponde a } 1,8 \mathrm{~m}^{2} \text { (AMERICAN..., } \\
\text { 2013). Taxa metabólica referente à atividade de } \\
\text { escritório - digitação (CENTRO..., 2014) }\end{array}$ \\
\hline \multirow{2}{*}{$\begin{array}{l}\text { Equipamentos } \\
\text { (computadores) }\end{array}$} & $\begin{array}{l}\text { Densidade } \\
\left(\mathrm{W} / \mathrm{m}^{2}\right)\end{array}$ & 10,7 & Densidade média - NBR 16401-1 (ABNT, 2008b) \\
\hline & Fator radiante & 0,3 & Documentação do EnergyPlus (CENTRO..., 2014) \\
\hline \multirow{2}{*}{ Iluminação } & $\begin{array}{l}\text { Densidade } \\
\left(\mathrm{W} / \mathrm{m}^{2}\right)\end{array}$ & 9,7 & Nível A do RTQ-C (INSTITUTO..., 2014) \\
\hline & $\begin{array}{l}\text { Padrão de uso } \\
\text { (horas) }\end{array}$ & Dimerizável & Simulação do DIVA-for-Rhino (SOLEMMA, 2014) \\
\hline
\end{tabular}

No modo constante foram definidos dois padrões de uso para o termostato do ar-condicionado, que funcionam de maneira a manter a temperatura de controle de $18{ }^{\circ} \mathrm{C}$ para aquecimento e de $25^{\circ} \mathrm{C}$ para resfriamento durante a semana, no período ocupado, e as janelas permanecem sempre fechadas.

Por outro lado, o modo misto é caracterizado pela combinação do uso da ventilação natural, sempre que possível, com o ar-condicionado, somente quando necessário. Essa integração foi feita através de padrões de uso para controlar os momentos em que a ventilação ou o arcondicionado seriam acionados na simulação. Em relação à avaliação do conforto térmico, apesar de estudos indicarem quais são os métodos que mais se adaptam para edifícios híbridos, como o do conforto adaptativo, presente nas normas ANSI/ASHRAE Standard 55 (AMERICAN..., 2013) e EN 15251 (COMITÉ..., 2007), e o método de Givoni (1992), ainda não existe um específico para esse tipo de edificação (DE VECCHI, 2015; DEUBLE; DE DEAR, 2012; RUPP; GHISI, 2014). Dessa forma, o controle foi feito através de definições de temperaturas (Figura 6) somente para o período ocupado:

(a) $18^{\circ} \mathrm{C}$ para permitir o acionamento do arcondicionado para aquecimento (BRUGNERA, 2014);

(b) $20^{\circ} \mathrm{C}$ para permitir o uso da ventilação natural (INSTITUTO..., 2010; DEUBLE; DE DEAR, 2012) - ocorre quando a temperatura do ar interior for maior que a temperatura do ar exterior, $\mathrm{Ti}>\mathrm{Te}$, e quando a temperatura do ar interior for maior que a temperatura de controle da ventilação estabelecida, $\mathrm{Ti}>\mathrm{TCv}$; e (c) $25^{\circ} \mathrm{C}$ para permitir o acionamento do arcondicionado no modo de resfriamento (BRUGNERA, 2014; DE VECCHI, 2015; DEUBLE; DE DEAR, 2012; DRAKE et al., 2010; KARAVA et al., 2012).

Para a modelagem da ventilação natural foi utilizado o objeto Airflow Network do EnergyPlus. Este é considerado o objeto mais preciso do programa, capaz de simular o fluxo de ar, forçado ou natural, entre o interior do ambiente e o exterior através de frestas e aberturas (CENTRO..., 2014). Os dados de entrada foram definidos tendo-se como referência os trabalhos de Brugnera (2014) e de Rupp (2011) e o manual de simulação computacional de edifícios naturalmente ventilados no EnergyPlus (PEREIRA et al., 2013). Os coeficientes de pressão do vento foram considerados médios para cada fachada, calculados automaticamente pelo próprio programa. Nesse tipo de edifício as salas permanecem com as portas internas fechadas, e as janelas podem ser abertas pelos usuários, sendo esta uma característica comum de operação. Isso significa que o tipo de ventilação natural que pode ocorrer no ambiente é unilateral, ou seja, ela ocorre a partir de uma turbulência do vento próxima à abertura (STABAT; CACIOLO; MARCHIO, 2012). Esse tipo de ventilação foi configurado no Airflow Network mantendo-se a porta interna fechada e as janelas abrindo conforme os padrões definidos anteriormente (Figura 6), a partir do grupo Airflow Network Multi Zone Surface. As janelas foram consideradas do tipo não pivotante, o que representa uma abertura efetiva de $100 \%$ do vão. 
Figura 6 - Temperaturas de controle do ar-condicionado e da ventilação natural para o período ocupado

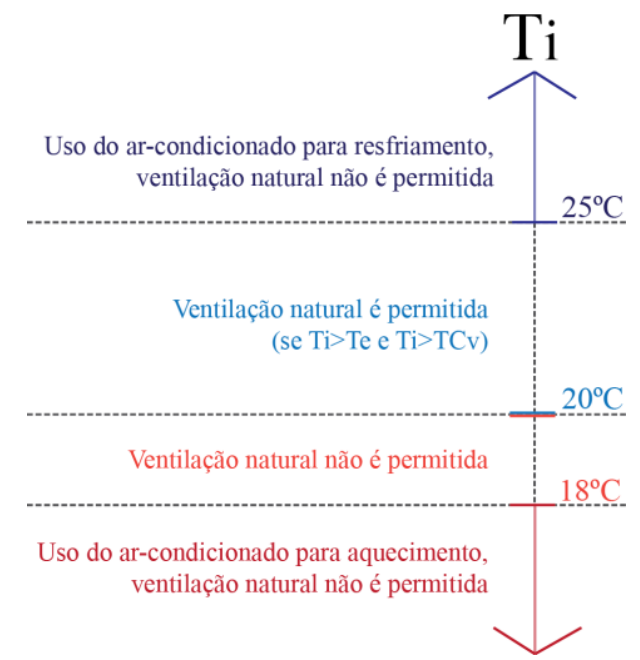

Por fim, o funcionamento desses sistemas pode ser verificado com o gerenciador de ventilação híbrida, Availability Manager Hybrid Ventilation, que indica os horários de desligamento/ acionamento do ar-condicionado e o uso da ventilação natural.

\section{Total de simulações e influência de outros parâmetros}

Foram realizadas simulações com os cinco modelos de salas de escritório (modelos 1:3, 1:2, $1: 1,2: 1,3: 1)$ operando com o ar-condicionado durante todo o ano nos horários de ocupação (modo constante) e com a ventilação híbrida (modo misto) e suas variações principais (PAF de $10 \%, 40 \%, 70 \%$ e $100 \%$ e orientações norte-sul, leste-oeste) no EnergyPlus (80 simulações) eDIVA-for-Rhino (40 simulações, desconsiderando a variação de modo de operação da sala). Posteriormente, mediante a primeira análise dos resultados dessas simulações e para uma análise mais específica para os modelos com o modo misto, foram escolhidos casos que indicaram possibilidades de maior impacto no consumo de energia a partir da variação de outros parâmetros. Dessa forma, modelos operando no modo misto e com todos os PAFs (para se observar a influência em todas as áreas de abertura) foram escolhidos para realizar uma última sequência de simulações, sendo elas relacionadas a:

(a) alteração de parâmetros de projeto: como é de uso comum as janelas não possuírem aberturas de $100 \%$ do vão em salas de escritório, alterou-se a abertura efetiva para ventilação da janela de $100 \%$ para $50 \%$ para o modelo $1: 3$, orientação norte, e para o modelo 1:1, orientação sul. (b) alteração de parâmetros de uso ${ }^{1}$ : devido ao fato de a carga térmica interna ter grande influência no consumo de energia do arcondicionado, alterou-se a carga térmica dos equipamentos de média para alta $\left(21,5 \mathrm{~W} / \mathrm{m}^{2}\right)$ para o modelo $1: 3$, orientação norte, e para leve $(5,4$ $\mathrm{W} / \mathrm{m}^{2}$ ) para o modelo $3: 1$, orientação norte (ABNT, 2008b). Também para se observar a influência da alteração da temperatura de controle do acionamento do ar-condicionado para resfriamento no consumo energético, alterou-se a temperatura em apenas $1^{\circ} \mathrm{C}\left(\mathrm{de} 25^{\circ} \mathrm{C}\right.$ para $\left.26^{\circ} \mathrm{C}\right)$, para o modelo $3: 1$, orientação norte.

Devido ao teor dessas simulações, não foi preciso realizar mais simulações no DIVA-for-Rhino, e, sim, somente no EnergyPlus (20 simulações), totalizando, portanto, neste trabalho 140 simulações (100 no EnergyPlus e 40 no DIVA-forRhino).

\section{Forma de análise dos resultados}

Primeiramente, observou-se a influência dos parâmetros de projeto no acionamento do arcondicionado nos modos constante e misto, e na abertura das janelas ao longo dos meses do ano, elencando-se padrões e comparando-se diferenças e semelhanças entre todos os modelos. Posteriormente foram observados os impactos dos parâmetros na redução e no consumo de energia do ar-condicionado, comparando-se as salas operando nos modos constante e misto, e o quanto essa

\footnotetext{
${ }^{1}$ Parâmetros de uso: neste trabalho parâmetros de uso foram considerados como características internas da sala, como a quantidade de equipamentos e a temperatura de acionamento do aparelho de ar condicionado.
} 
redução representou no consumo energético total das salas de escritório.

Neste trabalho, como forma de simplificação e devido ao fato de os resultados terem relações comparativas, o sistema mecânico simulado foi o ar-condicionado ideal que possui eficiência energética de $100 \%$, ou seja, capacidade de resfriamento/aquecimento igual à potência de energia consumida (coeficiente de eficiência energética - CEE, de $1 \mathrm{~W} / \mathrm{W})$. Contudo, para o cálculo do consumo de energia total e do arcondicionado para resfriamento, o ar-condicionado ideal foi convertido para split para que os valores se aproximassem de um sistema real, podendo ser comparável com os outros consumos (equipamentos e luz). Essa conversão foi realizada a partir da alteração de seu nível de eficiência (CEE) de $1 \mathrm{~W} / \mathrm{W}$ para o valor mais comum encontrado de um ar-condicionado real split, de 3,24 W/W (INSTITUTO..., 2016). Já o consumo no modo de aquecimento do ar-condicionado foi desconsiderado, porque,devido ao clima estudado, representou, em média, apenas $2 \%$ do total consumido pelo sistema.

Por fim, foram estabelecidas faixas de consumo de energia de $\mathrm{A}$ a $\mathrm{C}$ do ar-condicionado operando no modo misto. Esse processo foi realizado dividindose os valores do consumo energético do arcondicionado para resfriamento em três faixas, tendo como extremos o mínimo e o máximo obtidos nas variações principais dos modelos, conforme mostra a Tabela 3 .

\section{Resultados e discussão}

\section{Acionamento do ar-condicionado nos modos constante e misto e ocorrência de ventilação natural no modo misto}

A Figura 7 apresenta a porcentagem das horas ocupadas de cada mês em que o ar-condicionado é acionado para resfriamento $\left(\mathrm{Ti}>=25^{\circ} \mathrm{C}\right)$ para $\mathrm{o}$ modelo 1:1, com orientação norte e PAF de $40 \%$, simulado tanto no modo constante (arcondicionado constante) quanto no modo misto (com ventilação híbrida) na cidade de São Paulo. No modo constante é necessário que o arcondicionado seja acionado mais de $90 \%$ das horas do período ocupado em todos os meses do ano para manter a temperatura interna em, no máximo, $25{ }^{\circ} \mathrm{C}$. Nas poucas horas restantes o arcondicionado é desligado $\left(\mathrm{Ti}<25^{\circ} \mathrm{C}\right)$ e as janelas continuam fechadas. Por outro lado, ao se utilizar o modo misto, o uso do ar-condicionado corresponde de $21 \%$ a $87 \%$ das horas ocupadas mensais, sendo na quase totalidade do tempo restante a redução da temperatura interior realizada pela ventilação natural. Foram observadas raras horas em que não houve abertura das janelas e não foi ligado o sistema mecânico para esse clima. Isso porque a temperatura interna permaneceu quase sempre entre a temperatura de controle da ventilação natural $\left(20^{\circ} \mathrm{C}\right)$ e a temperatura de acionamento do ar-condicionado $\left(25^{\circ} \mathrm{C}\right)$, além de permanecer maior que a temperatura externa $(\mathrm{Ti}>\mathrm{Te})$.

Em seguida, ainda na Figura 7, têm-se os dados anuais para os seguintes casos:

(a) o mesmo modelo de sala de escritório (modelo $1: 1)$, orientação norte e PAFs variados $(10 \%, 70 \%$ e $100 \%)$;

(b) o mesmo modelo (modelo 1:1) com PAF $(40 \%)$, mas com orientações variadas (norte, leste, oeste e sul); e

(c) todos os outros modelos (modelos 1:3, 1:2, 2:1 e $3: 1$ ) com orientação norte e PAF de $40 \%$.

Tabela 3 - Faixas de consumo de energia com o modo misto

\begin{tabular}{c|c|c}
\hline \multicolumn{3}{|c}{ Faixas de consumo } \\
\hline Faixa A & Faixa B & Faixa $C$ \\
\hline $\mathrm{V}<$ Mín+1C & Mín $+1 \mathrm{C} \leq \mathrm{V}<$ Mín $+2 \mathrm{C}$ & $\mathrm{V} \geq$ Mín $+2 \mathrm{C}$ \\
\hline
\end{tabular}

Nota: Legenda:

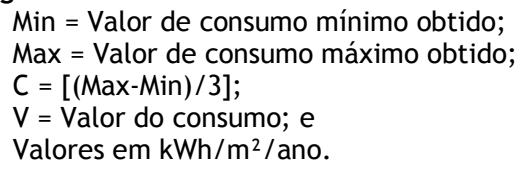


Figura 7 - Acionamento do ar-condicionado e abertura das janelas durante as horas ocupadas

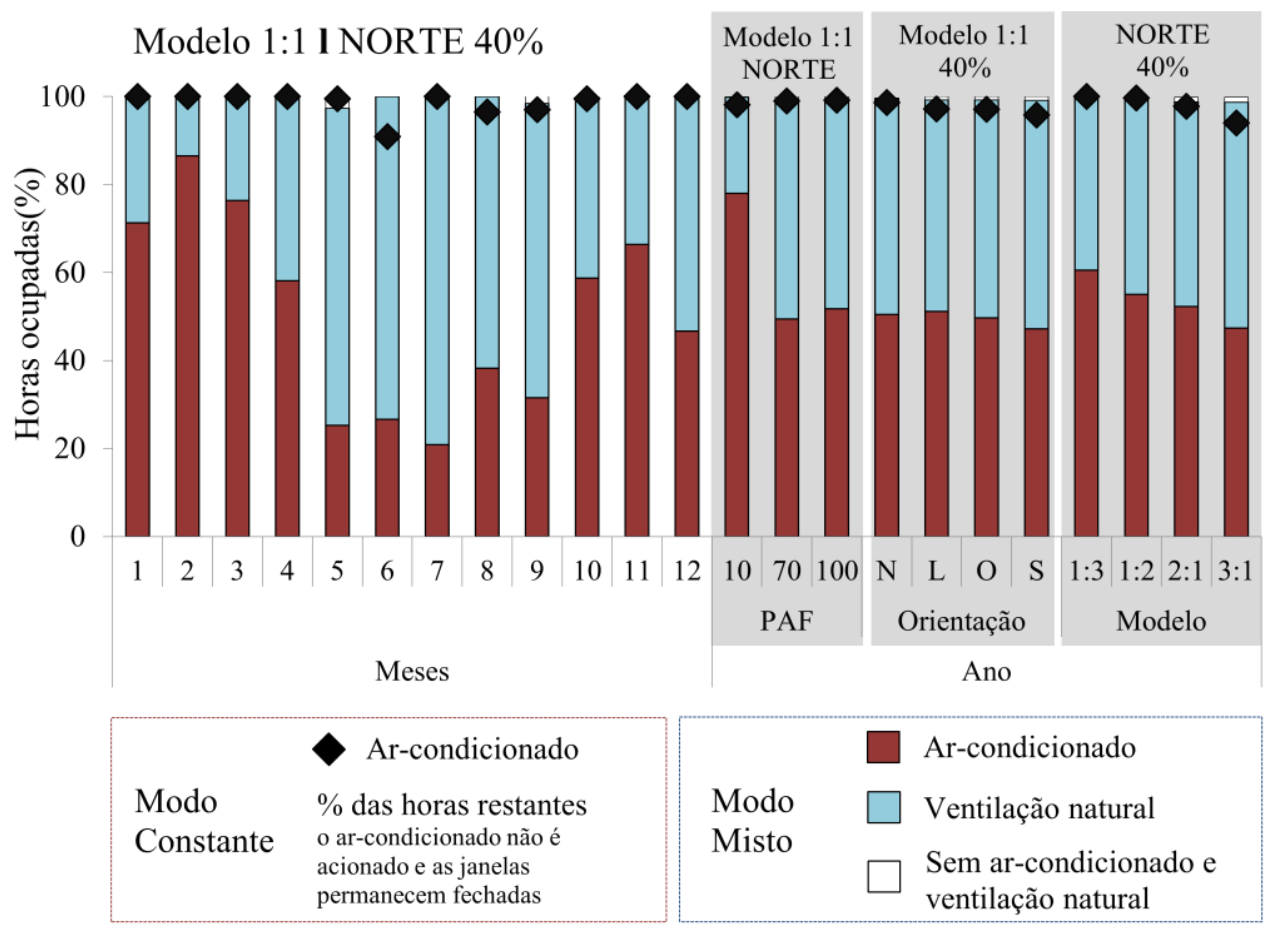

Esses resultados foram selecionados para apresentar o padrão de funcionamento das duas estratégias de resfriamento do ambiente (modos constante e misto), visto que as outras simulações seguiram a mesma tendência. Observa-se que o padrão de funcionamento anual dos modos constante e misto difere para a menor a área de abertura na fachada (PAF de 10\%). Com o PAF de $10 \%$ o ar-condicionado é acionado mais de $70 \%$ das horas do período ocupado no ano, enquanto para os outros PAFs (70\% e 100\%) ele é acionado menos de $52 \%$ das horas desse mesmo período. Isso ocorre devido à pequena área de janela, que limita a eficácia da ventilação natural. Contudo, não foram observadas alterações significativas no padrão em outras orientações (norte, leste, oeste e sul) e nos outros casos (modelos 1:3, 1:2, 2:1 e $3: 1$ ), exceto para os casos com PAF de $10 \%$, como já mencionado, o que indica que as condições são propícias para se utilizar o modo misto para o clima e o tipo de edifício estudado.

A diferença de padrão observada na Figura 7 (para o PAF de $10 \%$ ) pode ser observada na Figura 8, que se refere ao modelo $1: 1$ e orientação norte, com os PAFs de 10\% (Figura 8a) e 100\% (Figura $8 b)$. São observados os valores médios mensais horários das seguintes variáveis: temperaturas do ar exterior (Te), interior ( $\mathrm{Ti}$ ) e de controle (tanto para o acionamento do ar-condicionado, $\mathrm{TCa}$ ) como para a ventilação natural, $\mathrm{TCv}$ ); e as renovações de ar por hora que ocorrem no ambiente. Destacam-se quatro meses considerados representativos dos períodos de verão (fevereiro), inverno (junho) e de meia-estação, outono (abril) e primavera (outubro).

$\mathrm{Na}$ Figura 8a observa-se que, com a janela pequena (PAF de 10\%), não se consegue obter uma ventilação natural eficiente no ambiente, ocorrendo mínimas renovações de ar por hora. Isso faz com que a temperatura interna permaneça elevada, o que exige que o ar-condicionado seja acionado na maior parte das horas para manter a temperatura interna satisfatória.

Como as janelas médias e maiores (PAFs de $40 \%$, $70 \%$ e $100 \%$ ) possuem comportamento semelhante, na Figura $8 \mathrm{~b}$ foram apresentadas as horas em que acontece o acionamento do arcondicionado ou a abertura das janelas com a maior janela (PAF de 100\%). Em todos os meses, nas horas não ocupadas (noite e início do dia), a temperatura do ar interior é sempre superior à do exterior, havendo queda significativa às 8 horas da manhã, quando as janelas são abertas. No verão (fevereiro), as janelas são abertas principalmente no período da manhã, porém, com o aumento da temperatura do ar exterior e, consequentemente, do interior, a partir do final da manhã, é necessário fechar as janelas e ligar o ar-condicionado, que permanece ligado até o final do período ocupado. Em contrapartida, nos meses de inverno (junho) e de meia-estação (abril e outubro), a temperatura do ar exterior menor faz com que a temperatura do ar

128 Santesso, C. A.; Chvatal, K. M. S. 
interior permaneça na maior parte do período ocupado entre as faixas de controle de temperatura estabelecidas (de $20^{\circ} \mathrm{C}$ para a ventilação natural e de $25^{\circ} \mathrm{C}$ para o acionamento do ar-condicionado) principalmente no inverno, permitindo que as janelas fiquem abertas na maior parte das horas ocupadas, com maior uso da ventilação natural e poucas horas com ar-condicionado acionado.

Figura 8 - Valores médios mensais horários em cada estação do modelo 1:1, PAFs $10 \%$ e $100 \%$, orientação norte

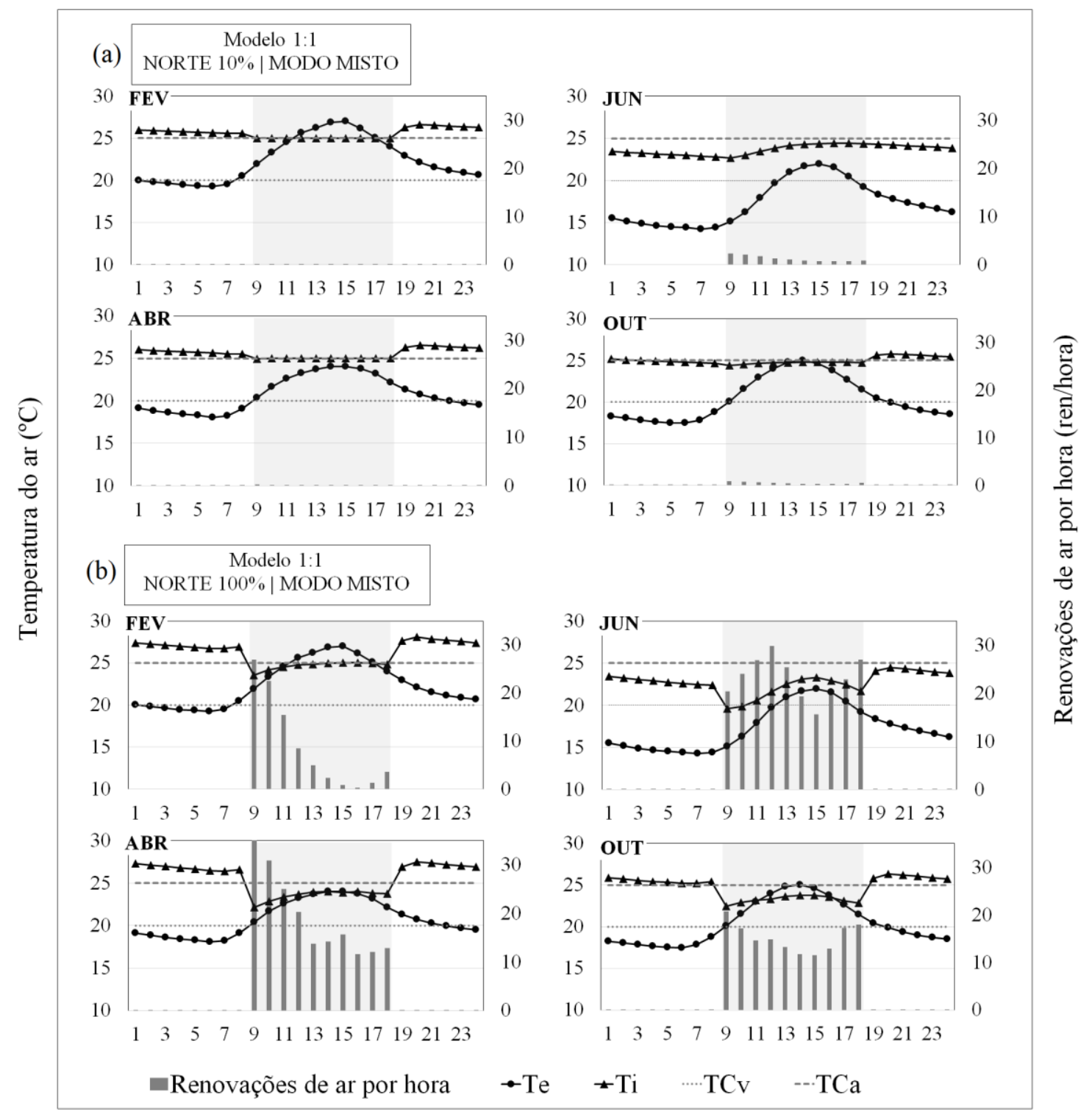

Valores médios mensais horários 


\section{Consumo de energia}

Nos resultados das simulações verificou-se que o impacto das alterações dos parâmetros no consumo de energia total (soma referente aos equipamentos, iluminação artificial e ar-condicionado para resfriamento) segue o mesmo padrão que o observado quando se considera apenas o consumo de energia do ar-condicionado. Isso porque, conforme indica a Figura 9, o consumo dos equipamentos é sempre o mesmo, não sendo modificado pelas variações dos parâmetros (28 $\mathrm{kWh} / \mathrm{m}^{2} / \mathrm{ano}$ ).Com relação à iluminação artificial (variação de consumo de 2 a $25 \mathrm{kWh} / \mathrm{m}^{2} / \mathrm{ano}$ ), como o sistema utilizado é dimerizável, apenas os casos com PAF de 10\% se situam próximos ao maior valor encontrado, sendo que os restantes apresentam baixo consumo.Já no que se refere ao ar-condicionado para resfriamento, seus consumos são os que apresentam as maiores variações (nos modos constante, de 12 a $44 \mathrm{kWh} / \mathrm{m}^{2} /$ ano, e misto, de 8 a $26 \mathrm{kWh} / \mathrm{m}^{2} / \mathrm{ano}$ ). Além disso, os consumos energéticos tanto dos equipamentos quanto da iluminação artificial têm influência no consumo de energia do ar-condicionado. Dessa maneira, na avaliação do consumo de energia do ambiente é dado enfoque ao consumo energético do arcondicionado para resfriamento, embora também sejam indicados, de forma mais sintética, os resultados referentes ao consumo total.

Dessa forma, a Figura 10 apresenta os consumos para resfriamento do ar-condicionado operando nos modos constante e misto de todas as simulações, separados de acordo com a orientação (norte, sul, leste e oeste), formato das salas (modelos $1: 3,1: 2,1: 1,2: 1$ e $3: 1)$ e PAFs $(10 \%$, $40 \%, 70 \%$ e $100 \%$ ) no clima estudado.

Para todos os modelos o modo constante é o que apresenta o maior consumo. Esse consumo reflete o maior tempo de acionamento do arcondicionado, conforme constatado anteriormente, pois ele é o único mecanismo de resfriamento do ambiente. Ao se alterar o uso do ar-condicionado do modo constante para o modo misto, foi possível atingir em todos os modelos redução do consumo do ar-condicionado, de $34,1 \%$ a $51,9 \%$, para os PAFs de $40 \%, 70 \%$ e $100 \%$, o que representou uma economia de energia no consumo total de $13,5 \%$ a $26,4 \%$. Destoou-se desse conjunto novamente (como verificado nas Figuras 7 e $8 \mathrm{a}$, anteriores) o PAF de $10 \%$, com menores reduções, de $1,7 \%$ a $30,5 \%$, do consumo energético do arcondicionado, gerando redução no consumo total de $0,6 \%$ a $9,4 \%$. Na literatura são encontrados resultados semelhantes em relação à redução do consumo de energia do sistema mecânico devido ao uso da ventilação híbrida, chegando-se a alcançar 30\% (BRUGNERA, 2014) e $40 \%$ (EZZELDIN; REES, 2013).

Como o uso da ventilação híbrida (modo misto) sempre representou economia em relação ao arcondicionado constante (modo constante), foram estabelecidas faixas de consumos, de A a C, conforme descrito na seção Método, para se observar como os parâmetros influenciam no consumo do ar-condicionado no modo misto (Figura 10).

Figura 9 - Relação entre os consumos de energia máximos e mínimos dos equipamentos, iluminação artificial e ar-condicionado para todas as simulações

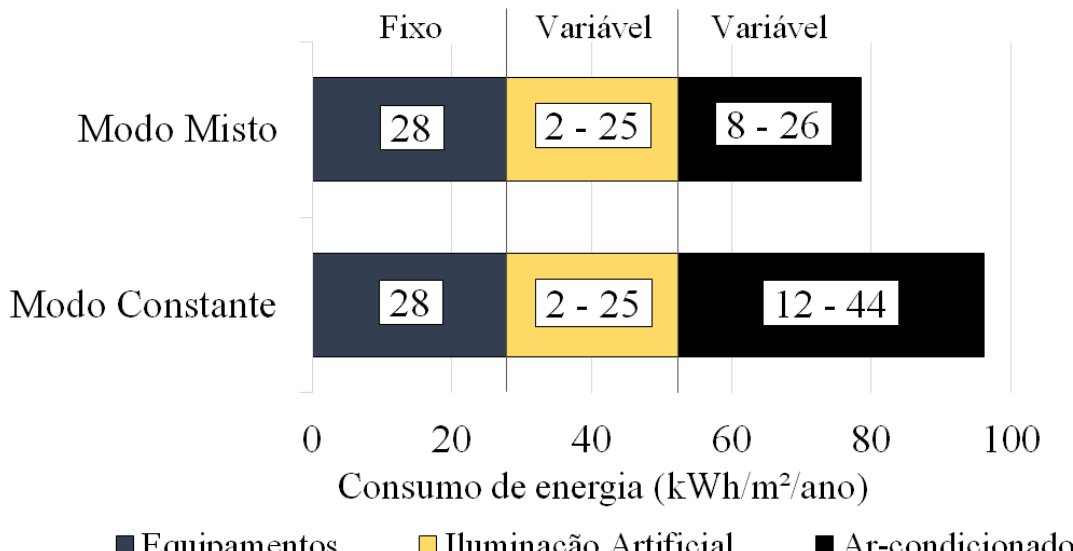

130 Santesso, C. A.; Chvatal, K. M. S. 
Figura 10 - Consumo do ar-condicionado com o modo constante e modo misto para todas as principais simulações

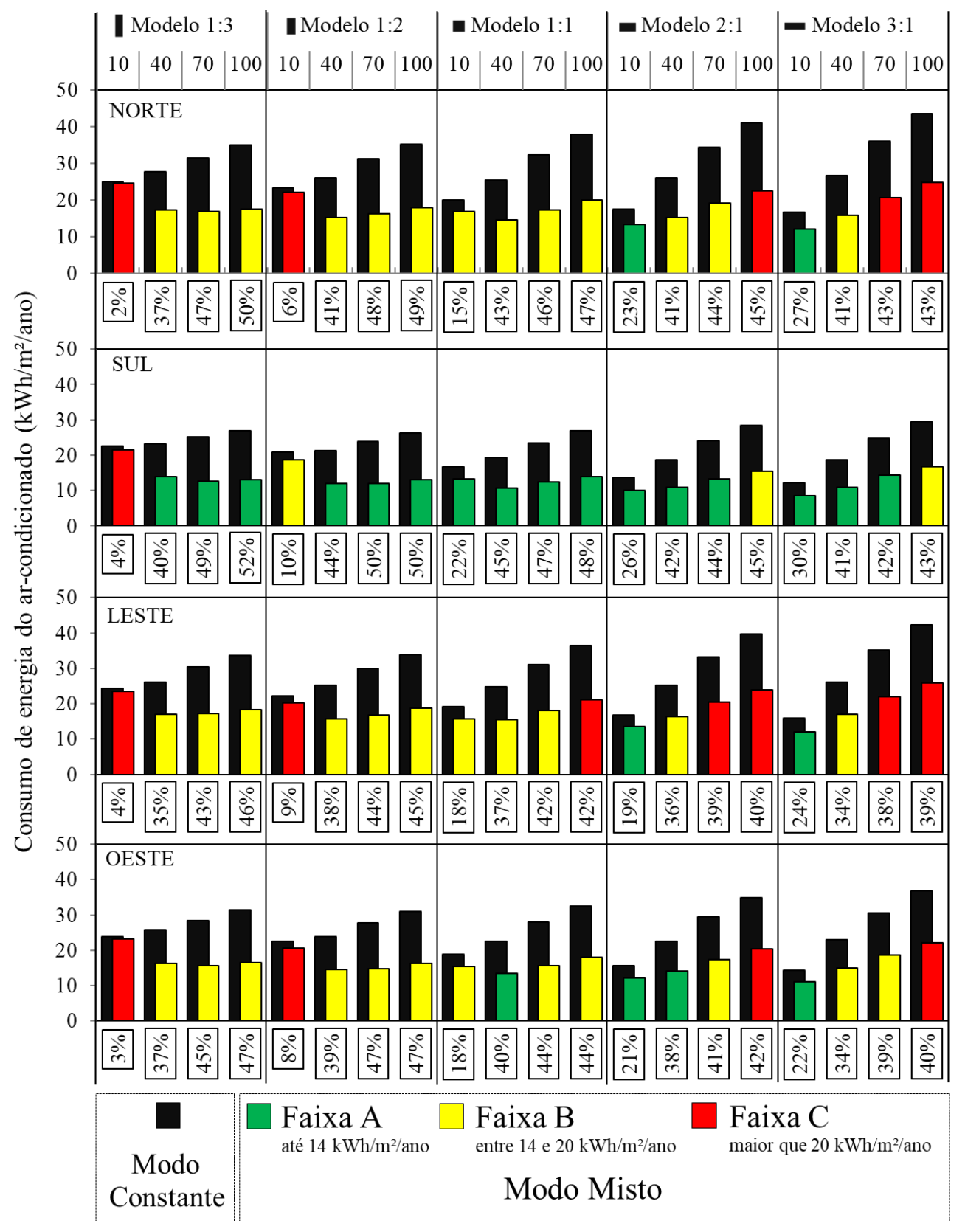

As salas mais profundas (modelos 1:3 e $1: 2$ ) conseguem alcançar menores consumos de energia utilizando janelas maiores (PAF entre $40 \%$ e $100 \%$ ). Devido ao fato de o formato da sala ser estreito e profundo, o aumento do tamanho da janela, que é localizada na menor fachada, não influencia de forma significativa o ganho de calor pelo vidro, mas é suficiente para aumentar a capacidade de resfriamento do ambiente pela ventilação natural. Assim, é possível passar da classificação da faixa C, com o PAF de $10 \%$, para a faixa B, com os PAFs de $40 \%, 70 \%$ e $100 \%$, nas orientações norte, leste e oeste. Na orientação sul, o consumo é ainda menor, conseguindo-se atingir até mesmo a faixa A. Isso porque esta orientação recebe menor radiação solar pelo vidro. Nesta orientação ainda é possível utilizar o PAF de $10 \%$ e permanecer na faixa B apenas para o modelo 1:2. Rupp e Ghisi (2012) também observaram que o uso da ventilação híbrida faz com seja possível utilizar áreas de abertura maiores na fachada, destacando a influência sobre o consumo de energia de forma semelhante a este estudo. Contudo, é importante observar que grandes janelas podem gerar risco de ofuscamento no ambiente ao se utilizar a iluminação natural sem o uso de proteções solares. 
O oposto acontece para salas mais largas (modelos 2:1 e 3:1), onde os menores consumos são caracterizados pela menor área de abertura (PAF de $10 \%$ ). Nesse caso, a influência do aumento do PAF é maior nessas geometrias, pois a área envidraçada está localizada na maior fachada. Assim, apesar de as salas serem largas e pouco profundas, a ventilação natural pode não ser suficiente para remover o calor em excesso devido ao elevado ganho de calor pelo vidro quando se utilizam janelas maiores. Verifica-se que há crescente aumento dos consumos a partir do PAF de $10 \%$, alterando-se da faixa $\mathrm{A}$ até a faixa $\mathrm{C}$, nas orientações norte, leste e oeste. A orientação sul novamente é exceção: apresenta os menores consumos e podem ser utilizadas até mesmo janelas maiores sem ultrapassar a faixa B. No mesmo trabalho realizado por Rupp e Ghisi (2012) reafirma-se essa questão para salas pequenas (até $12 \mathrm{~m}^{2}$ ) com geometria 2:1. Entretanto, utilizar janelas muito pequenas pode promover desconforto aos usuários do ambiente, por muitas vezes impedir o contato visual com o exterior ou mesmo não fornecer iluminação natural eficiente.

Para salas com formato quadrado (modelo 1:1) os menores consumos são alcançados com a janela de tamanho intermediário (PAF de 40\%). Isso porque janelas muito pequenas (PAF de 10\%) não permitem que o ambiente tenha uma ventilação natural eficaz, o que exige mais do arcondicionado, enquanto janelas muito grandes (PAFs de $70 \%$ e 100\%), apesar de promoverem melhor ventilação, não são suficientes para retirar o excesso de ganho de calor pelo vidro. Observa-se que nas orientações norte e leste o PAF de $40 \%$ encontra-se na faixa $B$ juntamente com quase todos os outros PAFs, excluindo-se na orientação leste o PAF de $100 \%$, que atinge a faixa C. Já na orientação oeste o PAF de $40 \%$ encontra-se na faixa $A$, enquanto os outros permanecem na faixa B. E, por fim, a orientação sul mais uma vez se destaca, com todos os modelos na faixa A.

Nota-se que entre todos os casos estudados (modelos 1:3, 1:2, 1:1, 2:1 e 3:1) as salas quadradas (modelo 1:1) apresentam mais situações com menores consumos de energia (faixa A) com o uso da ventilação híbrida. Ocorre somente uma situação em que há maior consumo de energia do ar-condicionado (faixa C). Portanto, a utilização de uma geometria quadrada de sala de escritório (com área de piso semelhante à estudada) possibilita maior quantidade de parâmetros de projeto (PAFs e orientações). Contudo, esses resultados com os modelos operando no modo misto podem sofrer alterações quando há outros parâmetros de projeto e de uso.

\section{Parâmetro de projeto: área efetiva de ventilação}

Os dados apresentados anteriormente correspondem ao consumo com o uso de janelas com abertura de $100 \%$ do vão. Ao se utilizarem outras janelas, os resultados podem ser diferentes dos apresentados. A Figura 11 compara os consumos dos modelos 1:3 e 1:1, orientação norte e sul respectivamente, no modo misto ao se alterar a abertura das janelas de $100 \%$ para $50 \%$ do vão.

Ao se utilizarem janelas com $50 \%$ do vão para a ventilação, ocorre aumento significativo do consumo no modo misto para os dois modelos apresentados, alterando-se até mesmo a faixa de consumo. Além disso, também pode ser observada mudança no padrão de consumo na sala mais profunda (modelo 1:3). Ela apresentava menores consumos com janelas maiores (PAFs de 40\%, $70 \%$ e $100 \%$ ), porém, com a alteração para $50 \%$, ela passa a ter menor consumo com a janela menor (PAF de 10\%), comportamento semelhante ao obtido anteriormente para as salas mais largas (modelos 2:1 e 3:1). Isso ocorre porque a janela possui a mesma dimensão de área envidraçada da simulação anterior, porém a área de abertura foi reduzida pela metade, diminuindo-se a eficiência da ventilação natural e gerando, consequentemente, aumento do consumo do arcondicionado para retirar o mesmo ganho de calor solar do ambiente. Assim, é interessante utilizar estratégias para o máximo aproveitamento da ventilação natural, desenvolvendo-se, por exemplo, esquadrias diferenciadas para as janelas.

\section{Parâmetros de uso: carga térmica de equipamentos e temperatura de controle do ar-condicionado}

Também é possível atingir variações do consumo de energia para os casos no modo misto quando se têm diferentes parâmetros de uso no ambiente, conforme indicado na Figura 12. 
Figura 11 - Consumo do ar-condicionado com o modo misto para modelos com aberturas dos vãos das janelas de $100 \%$ e $50 \%$
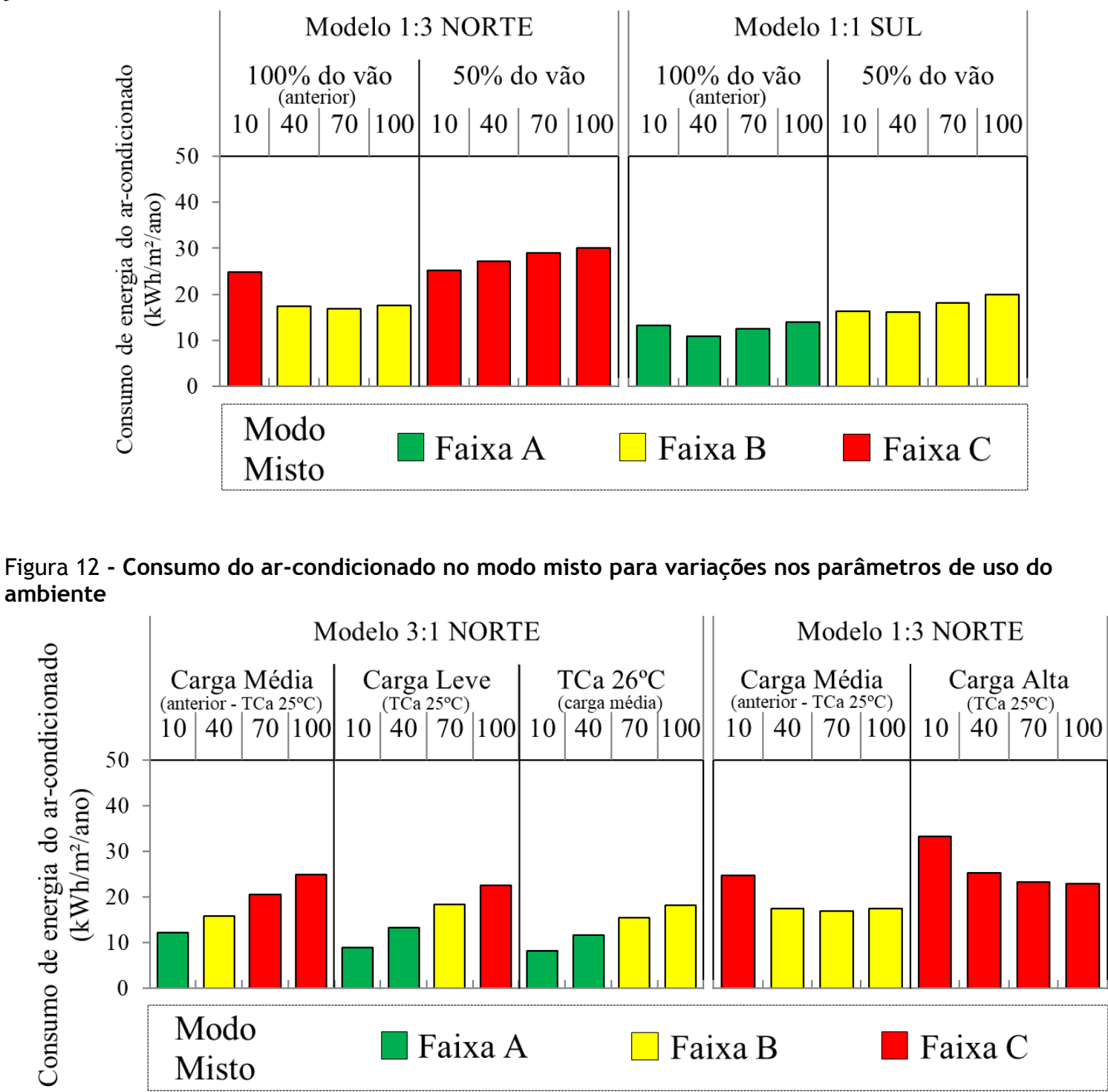

Com essas alterações nas simulações não foram observadas diferenças em relação aos padrões de consumo analisados anteriormente. No entanto, é possível atingir maior economia de energia quando o ambiente possui carga leve de equipamentos em vez de carga média (verificar Método) ou então quando se aumenta a temperatura de controle do ar-condicionado ( $\mathrm{TCa}$ de $26^{\circ} \mathrm{C}$ ), sendo possível até mesmo mudar a faixa de consumo em alguns casos (de C para B e de B para A). Um efeito negativo pode ocorrer, portanto, quando há cargas altas de equipamentos, sendo que para o modelo 1:3 todas as faixas de consumo passaram para a faixa C. Westphal e Lamberts (2007) e Brandalise (2015) já observaram esse fato e destacaram que as cargas internas de edifícios de escritórios têm grande influência em seu consumo de energia elétrica. Dessa forma, salas de escritório que possuem grande quantidade de equipamentos, como computadores e outros aparelhos eletrônicos, podem gerar superaquecimento no ambiente e, consequentemente, maior consumo do arcondicionado. Evidencia-se que é necessário que os parâmetros de uso sejam considerados também no processo de projeto de edificações de modo misto, pois podem tanto auxiliar como prejudicar a adoção da estratégia da ventilação híbrida.

\section{Conclusão}

O estudo teve como objetivo avaliar a influência de parâmetros arquitetônicos e de uso no consumo energético do ar-condicionado para resfriamento em salas de escritório com ventilação híbrida na cidade de São Paulo. Para isso foram utilizadas como metodologia simulações computacionais 
com o programa EnergyPlus. A sala simuladapossui área correspondente à média para essa tipologia $\left(36 \mathrm{~m}^{2}\right)$, além de ter ventilação unilateral, janela operável e ar-condicionado do tipo split. Entre os diferenciais deste trabalho observa-se que as análises foram realizadas para um ambiente de escritório já definido com elevado potencial para a utilização da ventilação híbrida. Além disso, para a definição das salas foi realizado um levantamento com edifícios reais na cidade de São Paulo, visto que ela possui grande quantidade desse tipo de edifício com representatividade nacional e internacional.

Como uma das principais conclusões do trabalho pode-se verificar que a ventilação híbrida sempre representou economia de energia, sendopossível atingir, em todos os modelos, a redução do consumo do ar-condicionado para resfriamento de $34 \%$ a $52 \%$ para os PAFs de $40 \%, 70 \%$ e $100 \%$ ( $13 \%$ a $26 \%$ do total), e de $2 \%$ a $30 \%$ para o PAF de $10 \%$ (1\% a $9 \%$ do total).

Além disso, para se obter o menor consumo do arcondicionado quando se utiliza o modo misto, é importante associar a forma da sala à área de abertura:

(a) salas mais estreitas e profundas (1:2 até 1:3) devem possuir janelas maiores (PAF de $40 \%$ a $100 \%)$;

(b) salas quadradas (1:1) devem possuir janelas intermediárias (PAF 40\%); e

(c) salas menos profundas e mais largas (2:1 até 3:1) devem possuir menores áreas de janela (PAF $10 \%)$.

Essas conclusões são alteradas quando se diminui a área de ventilação da janela, alterando o padrão observado. Na sala mais estreita e mais profunda (modelo 1:3), ao se alterar a área efetiva de ventilação de $100 \%$ para $50 \%$ do vão, o menor consumo passa a ser com a janela menor (PAF de $10 \%$ ), ao invés das janelas maiores.

Observou-se que maiores economias de energia podem ser alcançadas quando as salas possuem cargas internas menores (como densidade leve de equipamentos). $\mathrm{E}$, ainda, que a alteração de apenas $1{ }^{\circ} \mathrm{C}$ de acionamento do ar-condicionado (de $25^{\circ} \mathrm{C}$ para $26^{\circ} \mathrm{C}$ ) representa reduções significativas no ambiente, da ordem de $30 \%$ no consumo energético do ar-condicionado.

Quanto às limitações deste estudo, é importante ressaltar que os resultados são analisados considerando-se uma área média de sala de escritório com controle de operação ideal, representando situações com o máximo aproveitamento da ventilação natural no modo misto e, portanto, menor consumo energético do ar-condicionado.

Para trabalhos futuros, sugere-se maior aprofundamento em análises de edificações de modo misto que analisem tanto o desempenho termoenergético quanto o conforto visual, considerando a integração da iluminação natural e elementos de proteção solar para se evitarem riscos de ofuscamento. Seria interessante variar outros parâmetros arquitetônicos e de uso nessas mesmas salas de escritório, buscando aumentar a eficiência da ventilação natural, como, por exemplo, a partir da ventilação cruzada. Estudos de campo em edificações de modo misto brasileiras também seriam interessantes para poder prever de forma mais adequada o comportamento dos usuários na simulação, assim como o desenvolvimento de índices de conforto que se enquadrem melhor para essa tipologia de edifício. Por fim, poderiam ser utilizadas outras metodologias de estudo, como medições em túnel de vento e simulações em programas computacionais de dinâmica dos fluidos (CFD), ou ainda calibrar um modelo de sala com resultados em campo.

\section{Referências}
AMERICAN SOCIETY OF HEATING, REFRIGERATING AND AIRCONDITIONING ENGINEERS. ANSI/ASHRAE Standard 140: standard method of test for the evaluation of building energy analysis computer programs. Atlanta, 2004.

\section{AMERICAN SOCIETY OF HEATING, REFRIGERATING AND AIRCONDITIONING ENGINEERS. ANSI/ASHRAE Standard 55: thermal environmental conditions for human occupancy. Atlanta, 2013.}

\section{ASSOCIAÇÃO BRASILEIRA DE NORMAS} TÉCNICAS. NBR 15215-4: iluminação natural: parte 4: verificação experimental das condições de iluminação interna de edificações: método de medição. Rio de Janeiro, 2004.

\section{ASSOCIAÇÃO BRASILEIRA DE NORMAS TÉCNICAS. NBR 15220-2: desempenho térmico de edificações: parte 2 : métodos de cálculo da transmitância térmica, da capacidade térmica, do atraso térmico e do fator solar de elementos e componentes de edificações. Rio de Janeiro, $2005 b$.}

\section{ASSOCIAÇÃO BRASILEIRA DE NORMAS}

TÉCNICAS. NBR 15220-3: desempenho térmico de edificações: parte 3: zoneamento bioclimático brasileiro e diretrizes construtivas para habitações unifamiliares de interesse social. Rio de Janeiro, 2005a. 
ASSOCIAÇÃO BRASILEIRA DE NORMAS TÉCNICAS. NBR 16401-1: instalações de arcondicionado, sistemas centrais e unitários: parte 1: projetos das instalações. Rio de Janeiro, 2008b.

ASSOCIAÇÃO BRASILEIRA DE NORMAS TÉCNICAS. NBR 16401-3: instalações de arcondicionado, sistemas centrais e unitários: parte 2: parâmetros de conforto térmico. Rio de Janeiro, 2008a.

ASSOCIAÇÃO BRASILEIRA DE NORMAS TÉCNICAS. NBR 9077: saídas de emergência em edifícios. Rio de Janeiro, 2001.

ASSOCIAÇÃO BRASILEIRA DE NORMAS TÉCNICAS. NBR ISO/CIE 8995: iluminação de ambientes de trabalho: parte 1: interior. Rio de Janeiro, 2013.

BRAGER, G. S.; RING, E.; POWELL, K. MixedMode Ventilation: HVAC Meets Mother Nature. Engineered Systems, p. 60-70, may 2000.

BRANDALISE, M. P. Análise da Sensibilidade do RTQ-C Quanto à Variação da Densidade de Carga Interna. Pelotas, 2015. 172 f. Dissertação (Mestrado em Engenharia Civil) - Faculdade de Arquitetura e Urbanismo, Universidade Federal de Pelotas, Pelotas, 2015.

BRASIL. Código de Obras e Edificações: Lei $n^{\circ}$ 11.228/92. São Paulo, 1992.

BRUGNERA, R. R. Potencial de Economia de Energia em Edifícios de Escritórios Com Estratégias de Ventilação Híbrida. São Carlos, 2014. 76 f. Dissertação (Mestrado em Engenharia Civil) - Instituto de Arquitetura e Urbanismo, Universidade de São Paulo, São Carlos, 2014.

BUILDINGS. Pesquisa Imobiliária Inteligente: primeira empresa brasileira especializada em pesquisa imobiliária corporativa. Disponível em: <http://www.buildings.com.br>. Acesso em: 18 abr. 2016.

CARRIÈRES, K. R. M. Desempenho Térmico e Consumo Energético de Edifícios de Escritórios em São Carlos, SP. Campinas, 2007. 151 f. Dissertação (Mestrado em Engenharia Civil) Faculdade de Engenharia Civil, Arquitetura e Urbanismo, Universidade Estadual de Campinas, Campinas, 2007.

CENTER FOR THE BUILT ENVIRONMENT.

About Mixed Mode. University of California, Berkeley. Disponível em:

<http://www.cbe.berkeley.edu/mixedmode/aboutm m.html>. Acesso em: 12 dez. 2017.
CENTRO DE PESQUISAS

METEOROLÓGICAS E CLIMÁTICAS

APLICADAS À AGRICULTURA. Clima dos

Municípios Paulistas. Disponível em:

$<$ http://www.cpa.unicamp.br/outras-

informacoes/clima-dos-municipiospaulistas.html>.

Acesso em: 11 dez. 2016.

COMITÉ EUROPEEN DE NORMALISATION.

EN15251: indoor environmental input parameters for design and assessment of energy performance of buildings: addressing indoor air quality, thermal environment, lighting and acoustics. Brussels, 2007.

DE VECCHI, R. Avaliação de Conforto Térmico em Edificações Comerciais Que Operam Sob Sistemas Mistos de Condicionamento Ambiental em Clima Temperado e Úmido. Florianópolis, 2015. 118 f. Tese (Doutorado em Engenharia Civil) - Centro Tecnológico, Universidade Federal de Santa Catarina, Florianópolis, 2015.

\section{DEPARTMENT OF ENERGY EFFICIENCY} AND RENEWABLE ENERGY. EnergyPlus: version 8.2.0. Department of Energy Efficiency and Renewable. Disponível

em:<https://energyplus.net/>. Acesso em: 31 jul. 2014.

DEUBLE, M. P.; DE DEAR, R. J. Mixed-Mode Buildings: a double standard in occupants' comfort expectations. Building and Environment, v. 54, p. 53-60, 2012.

DORNELLES, K. A. Absortância Solar de Superfícies Opacas: métodos de determinação e base de dados para tintas látex acrílica e PVA. Campinas, 2008. 80 f. Tese (Doutorado em Engenharia Civil) - Faculdade de Engenharia Civil, Arquitetura e Urbanismo,

UniversidadeEstadual de Campinas, Campinas, 2008.

DRAKE, S. et al. Occupant Comfort in Naturally Ventilated and Mixed-Mode Spaces Within AirConditioned Offices. Architectural Science Review, v. 53, p. 297-306, 2010.

EZZELDIN, S.; REES, S. J. The Potential For Office Buildings With Mixed-Mode Ventilation and Low Energy Cooling Systems in Arid Climates. Energy and Buildings, v. 65, p. 368381, 2013.

GHISI, E. The Use of Fibre Optics on Energy Efficient Lighting in Buildings. Leeds, 2002. 312 f. Tese (Doutorado em Engenharia Civil) Faculdade de Engenharia Civil, Universidade de Leeds, Leeds, 2002. 
GHISI, E.; TINKER, J. A.; IBRAHIM, S. H. Área de Janela e Dimensões de Ambientes Para Iluminação Natural e Eficiência Energética: literatura versus simulação computacional. Ambiente Construído, v. 5, n. 4, p. 81-93, out./dez. 2005.

GIVONI, B. Comfort, Climate Analysis and Building Design Guidelines. Energy and Buildings, v. 18, p. 11-23, 1992.

GONÇALVES, J. C. S.; BODE, K. Edifício Ambiental. São Paulo: Oficina de Textos, 2015.

HU. J.; KARAVA, P. Model Predictive Control Strategies For Buildings With Mixed-Mode Cooling. Building and Environment, v. 71, p. 233-244, 2014.

INSTITUTO NACIONAL DE METROLOGIA, NORMALIZAÇÃO E QUALIDADE

INDUSTRIAL. RTQ-R: regulamento técnico da qualidade para o nível de eficiência energética em edificações residenciais. Rio de Janeiro, 2010.

INSTITUTO NACIONAL DE METROLOGIA, NORMALIZAÇÃO E QUALIDADE

INDUSTRIAL. RTQ-C:regulamento técnico da qualidade para o nível de eficiênciaenergética de edificações comerciais, de serviços e públicas. Rio de Janeiro, 2014.

\section{INSTITUTO NACIONAL DE METROLOGIA,} NORMALIZAÇÃO E QUALIDADE

INDUSTRIAL. Condicionadores de Ar Split Hi-

Wall. Disponível em:

<http://www.inmetro.gov.br/consumidor/pbe/condi cionadores_ar_split_hiwall_indicenovo.pdf $>$. Acesso em: 7 maio 2016.

JI, Y.; LOMAS, K. J.; COOK, M. J. Hybrid Ventilation For Low Energy Building Design in South China. Building and Environment, v. 44, p. 2245-2255, 2009.

KARAVA, P. et al. Experimental Study of the Thermal Performance of a Large Institutional Building With Mixed-Mode Cooling and Hybrid Ventilation. Building and Environment, v. 57, p. 313-326, 2012.

\section{LABORATÓRIO DE EFICIÊNCIA}

ENERGÉTICA EM EDIFICAÇÕES; CRAWLEY, D.; LAWRIE, L. Arquivos Climáticos INMET 2015. 2015. Disponível em:

<http://www.labeee.ufsc.br/downloads/arquivosclimaticos/inmet2015>. Acesso em: 7 maio 2016.

MENASSA, C. C.; TAYLOR, N.; NELSON, J. A Framework For Automated Control and Commissioning of Hybrid Ventilation Systems in Complex Buildings. Automation in

Construction, v. 30, p. 94-103, 2013.
MENDLER, S.; ODELL, W.; LAZARUS, M. A. The HOK Guidebook to Sustainable Design. Nova York: Willey, 2006.

PEREIRA, H. A. C. P. et al. Manual de Simulação Computacional de Edifícios Naturalmente Ventilados no Programa EnergyPlus - Versão 8.0. Florianópolis, 2013.

RAMOS, G.; GHISI, E. Avaliação do Cálculo da Iluminação Natural Realizada Pelo Programa EnergyPlus. Ambiente Construído, Porto Alegre, v. 10, n. 2, p. 157-169, abr./jun. 2010.

REINHART, C. F.; WIENOLD, J. The Daylighting Dashboard: a simulation-based design analysis for daylit spaces. Building and Environment, v. 46, p. 386-396, 2011.

ROAF, S.; CRICHTON, D.; NICOL, F. A Adaptação de Edificações e Cidades às Mudanças Climáticas: um guia de sobrevivência para o século XXI. Porto Alegre: Bookman, 2009.

RORIZ, M. Base de Dados Climáticos de 411

Municípios Brasileiros: arquivos em formato de EPW (EnergyPlus Weather Data), 2012.

Disponível em:

<http://www.roriz.eng.br/epw_9.html>. Acesso em: 31 jul. 2014.

RORIZ, V. F.; RORIZ, M. EPvieW. 2015.

Disponível em: <https://goo.gl/AvVhva>. Acesso em: 7 maio 2016.

ROWE, D. A Study of a Mixed Mode Environment in 25 Cellular Offices at the University of Sydney. International Journal of Ventilation, v. 1, p. 53-64, 2003.

RUPP, R. F. Dimensionamento de Área de Janela em Edificações Comerciais: integração da iluminação natural com a artificial e utilização da ventilação hibrida. Florianópolis, $2011.106 \mathrm{f}$. Dissertação (Mestrado em Engenharia Civil) Centro Tecnológico, Universidade Federal de Santa Catarina, Florianópolis, 2011.

RUPP, R. F.; GHISI, E. Assessing Window Area and Potential For Electricity Savings by Using Daylighting and Hybrid Ventilation in Office Buildings in Southern Brazil. SimulationTransactions of the Society for Modeling and Simulation International, v. 93, n. 11, p. 935949, 2017.

RUPP, R. F.; GHISI, E. Potencial de Economia de Energia Elétrica em Edificações Comerciais Híbridas Localizadas em Florianópolis, SC. Ambiente Construído, Porto Alegre, v. 13, n. 1, p. 143-160, jan./mar. 2013a. 
RUPP, R. F.; GHISI, E. Potencial de Economia de Energia Elétrica Através do Uso da Luz Natural e da Ventilação Híbrida em Edifícios Comerciais em Florianópolis. Ambiente Construído, Porto Alegre, v. 13, n. 1, p. 75-86, jan./mar. 2013b.

RUPP, R. F.; GHISI, E. Sizing Window Areas For Daylighting and Hybrid Ventilation in Commercial Buildings. In: CONFERENCE, OPPORTUNITIES, LIMITS \& NEEDS TOWARDS AN ENVIRONMENTALLY RESPONSIBLE ARCHITECTURE, 28., Lima, 2012. Proceedings... Lima: PLEA, 2012.

RUPP, R. F.; GHISI, E. What Is the Most Adequate Method to Assess Thermal Comfort in Hybrid Commercial Buildings Located in HotHumid Summer Climate? Renewable \& Sustainable Energy Reviews, v. 29, p. 449-462, 2014.

SALCIDO, J. C.; RAHEEM, A. A.; ISSA, R. R. A. From Simulation to Monitoring: evaluating the potential of Mixed-Mode Ventilation (MMV) Systems For Integrating Natural Ventilation in Office Buildings Through a Comprehensive Literature Review. Energyand Buildings, v. 127, p. 1008-1018, 2016.
SOLEMMA. DIVA-for-Rhino Solemma LLC, 2014. Disponível em: 〈http://diva4rhino.com/>. Acesso em: 31 jul. 2014.

STABAT, P.; CACIOLO, M.; MARCHIO, D. Progress on Single-Sided Ventilation Techniques For Buildings. Advances in Building Energy Research, v. 6, p. 212-241, 2012.

WESTPHAL, F. S.; LAMBERTS, R. Análise do Impacto de Variáveis Arquitetônicas e Cargas Internas no Consumo de Energia em Condicionamento de Ar de Edificações Comerciais. In: ENCONTRO NACIONAL, 9.; ENCONTRO LATINO AMERICANO DE CONFORTO NO AMBIENTE CONSTRUÍDO, 5., Ouro Preto, 2007. Anais... Ouro Preto: ANTAC, 2007.

\section{Agradecimentos}

Os autores agradecem à Coordenação de Aperfeiçoamento de Pessoal de Nível Superior (Capes) pelo apoio e fomento a este trabalho de pesquisa.

Caroline Antonelli Sabtesso

Instituto de Arquitetura e Urbanismo | ${ }^{1}$ Universidade de São Paulo | Av. Trabalhador Sãocarlense, 400 | São Carlos - SP - Brasil | CEP 13566-590 | Tel.: (16) 3373-8600 | E-mail: caroline.santesso@gmail.com

Karin Maria Soares Chvatal

Instituto de Arquitetura e Urbanismo | Universidade de São Paulo | Av. Trabalhador Sãocarlense, 400 | São Carlos - SP - Brasil | CEP 13566-590 | Tel.: (16) 3373-8600 | E-mail: karin@sc.usp.br

Revista Ambiente Construído

Associação Nacional de Tecnologia do Ambiente Construído

Av. Osvaldo Aranha, $99-3^{\circ}$ andar, Centro

Porto Alegre - RS - Brasil

CEP 90035-190

Telefone: +55 (51) 3308-4084

Fax: +55 (51) 3308-4054

www.seer.ufrgs.br/ambienteconstruido

E-mail: ambienteconstruido@ufrgs.br

This is an open-access article distributed under the terms of the Creative Commons Attribution License. 